\title{
ANAEROBIC DIGESTION OF KITCHEN AND SEWAGE SLUDGE BIO WASTE TO BIOGAS USING ENGINEERED BIO CATALYSIS
}

\author{
Mercy M. Manyuchi ${ }^{1}$, Charles Mbohwa ${ }^{1}$ and Edison Muzenda ${ }^{2}$ \\ ${ }^{1}$ Department of Operations and Quality Management, Faculty of Engineering and the Built Environment, \\ University of Johannesburg, South Africa \\ ${ }^{2}$ Department of Chemical Engineering and Technology, Faculty of Engineering and the Built Environment, \\ University of Johannesburg, South Africa \\ Department of Chemical, Materials and Metallurgical Engineering, Faculty of Engineering and Technology, \\ Botswana International University of Science and Technology, P Bag 16, Palapye, Botswana
}

\begin{abstract}
In this study kitchen bio waste and sewage sludge were co-digested anaerobically to produce biogas with the aid of Hycura, engineering granules to enhance bio methane production. Co-digestion was conducted for mesophilic temperatures of $37^{\circ} \mathrm{C}$ in a $20 \mathrm{~L}$ bio digester for a period of 30 days. Kitchen and sewage sludge were inoculated in the ratio 50:50. Hycura was inoculated to enhance biogas production at a loading of $0.05 \mathrm{~g} / \mathrm{L}$. The co-digestion resulted in significant degrease of the total volatile solids and chemical oxygen demand of the bio waste by $>75 \%$. Mesophilic conditions favored high quality bio methane production with methane content as high as $74 \%$. Inoculation with Hycura hindered $\mathrm{H}_{2} \mathrm{~S}$ production which enhanced the quality of the biogas and makes it easier for upgrading.
\end{abstract}

\section{KEYWORDS}

Biogas, Bio-Waste, Co-Digestion, Hycura, Kitchen Waste, Sewage Sludge

\section{INTRODUCTION}

Huge amounts of biodegradable kitchen bio waste are being generated daily from the catering industry and at the same time municipal sewage plants are having challenges managing bio waste mainly sewage sludge. These bio wastes find themselves to the landfills limiting the life span of landfills. Sewage sludge and kitchen waste being highly organic material have both the have potential to be converted to biogas through anaerobic digestion (Muzenda, 2014). Kitchen waste has high calorific values compared to municipal waste hence presents an opportunity for biogas with high methane content (Gray et al., 2008; Apte et al., 2013).

Biogas is a good source of renewable energy that can be used for heating and cooking purposes and in some instances upgraded to electricity production (Neves et al., 2005; Prabhu and Mutnuri, 2009). Biogas production from the co-digestion of kitchen waste and sewage has become topical due to the increased digestion based on the number of microorganisms in the bio waste (Neves et al., 2005; Malik and Bharti, 2009). Production of biogas from bio waste is an attractive waste management initiative that promotes sustainability through the production of a renewable and green source of energy which mitigates climate change effects through reduction of carbon dioxide and methane emissions to the environment through co-digestion (Vikraut and Shekhar, 2013; Schaumann, 2013).

Biogas is produced in the four major steps which are hydrolysis, acidogenesis, acetogenesis and methanogenesis during the anaerobic digestion process (Das and Mondal, 2016). Figure 1 shows the biogas production stages from bio waste. Biogas from bio waste is mainly composed of methane with a composition of up to $65 \%$, carbon dioxide with a composition of up to $30 \%$ and traces (oxygen, ammonia and hydrogen sulphide) with a composition of up to $10 \%$ (Gray et. al., 2008). The biogas production rate and quality from several bio waste has mainly been affected by process conditions which include: the feedstock type, the digestion temperature, amount of total solids (TS), in the feedstock, the chemical oxygen demand (COD) of the bio waste, process temperature and the agitation effects (Manyuchi et al., 2015). 


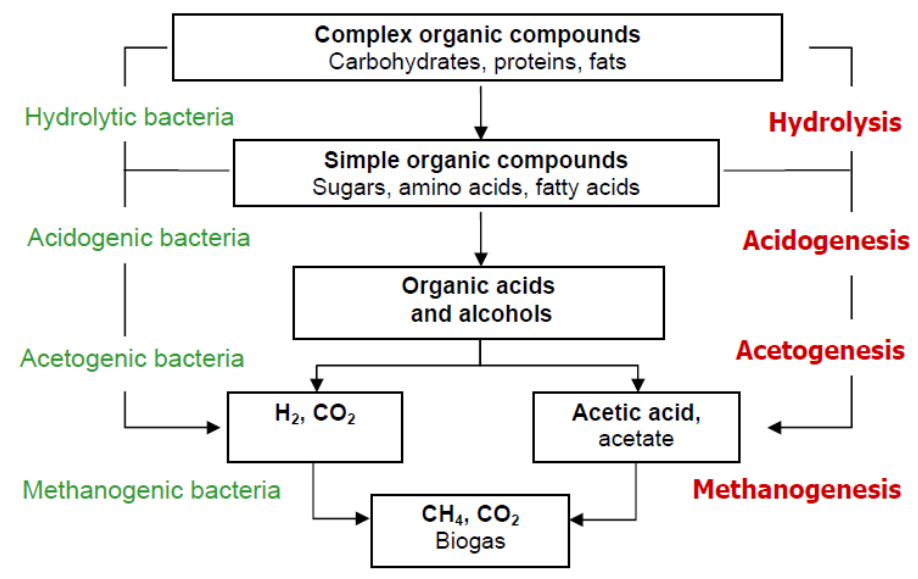

Figure 1. Biogas production stages (Das and Mondal, 2016)

On another note, bio catalysis of bio-waste to biogas using engineered enzymes has become topical as a means of enhancing the quality of the biogas in terms of the methane composition as well as the removal of impurities such as hydrogen sulphide and ammonia (Manyuchi et al., 2015). One enzyme being employed is Hycura, an enzyme bio catalyst, that potential to enhance biogas production through optimising methane production and hindering the production of hydrogen sulphide and ammonia and previous studies have reported that Hycura loadings of 0.035-0.05 g/L are optimal for biogas production (Manyuchi et al., 2015).

This study focused on the potential of co-digesting sewage sludge and kitchen bio waste to produce biogas utilizing Hycura, a biocatalyst that enhances biogas production. This was done in a bid to recover energy from the bio waste at the minimizing land filling problems potentially increasing the lifespan of landfills in general.

\section{MATERIALS AND METHODS}

\subsection{Materials}

Kitchen waste was obtained from a local canteen and sewage sludge was obtained from a nearby municipal sewage treatment plant in Harare, Zimbabwe. Hycura was obtained from Acti-zyme, Australia. A biogas analyzer model Biogas 5000 was obtained from Geotech, United Kingdom was used for the biogas composition analysis. A Mettler Toledo S20 pH meter from Sigma Aldrich, South Africa was used for the $\mathrm{pH}$ determination. A Memmert oven from Sunfirm Distributors, Harare, Zimbabwe was used for determination of the bio waste moisture content, the total solids (TS) and the volatile solids (VS) composition. A Hanna Instrument COD meter was used for COD determination and a TOC 5000 Shimadzu carbon analyzer from Sigma Aldrich, South Africa.

\subsection{Methods}

The kitchen waste and sewage sludge were mixed in a ratio of 50:50 and was allowed to co-digest in a $20 \mathrm{~L}$ digester over a 30 days retention time. To enhance the biogas production, $0.05 \mathrm{~g} / \mathrm{L}$ of Hycura was inoculated.

The bio waste $\mathrm{pH}$, chemical oxygen demand (COD), total solids (TS), total volatile solids (VS) and moisture content were measured using standard methodologies by APHA (2005). For the TS, a 5g well mixed sample was filtered through a filter with a known mass and the residue that remained was dried at $105 \pm 0.5^{\circ} \mathrm{C}$ in the oven for 1 hour. The increase in mass was determined as the TS as a percentage. The moisture content of the same sample was expressed at the net weight change as a percentage. The VS were 
measured by heating a $5 \mathrm{~g}$ sample at $550 \pm 0.5^{\circ} \mathrm{C}$ for 1 hour in the oven. Mesophilic conditions of $37 \pm 0.5^{\circ} \mathrm{C}$ were used for the co-digestion process (Sajeena et al., 2013; Dressa et al., 2015). The biogas was analyzed for its composition using a Biogas Analyzer 5000 during the anaerobic digestion period. Organic carbon loading measurements were done using a TOC 5000 Shimadzu carbon analyzer.

All experiments were determined thrice and an average value and the standard deviation calculated as a measure to check the repeatability of the experiments.

\section{RESULTS AND DISCUSSION}

\subsection{Effect of Process Parameters on Bio Waste Digestion}

\subsubsection{Organic Carbon Loading}

The blended kitchen and sewage sludge bio waste had an average organic carbon loading content of $95 \%$ and this was a clear indication that the blended waste is an attractive option for biogas production due to the high organic composition. Prabhu and Mutnuri (2016) also reported a high organic rate of more than $80 \%$ when they investigated the potential of co-digesting kitchen waste and other organic waste. As the anaerobic digestion process increased, the organic carbon loading rate decreased significantly with increase in the digestion period by about $82 \%$ (Figure 2). This showed the high degradation rate of the bio waste which showed effective biogas production rates.

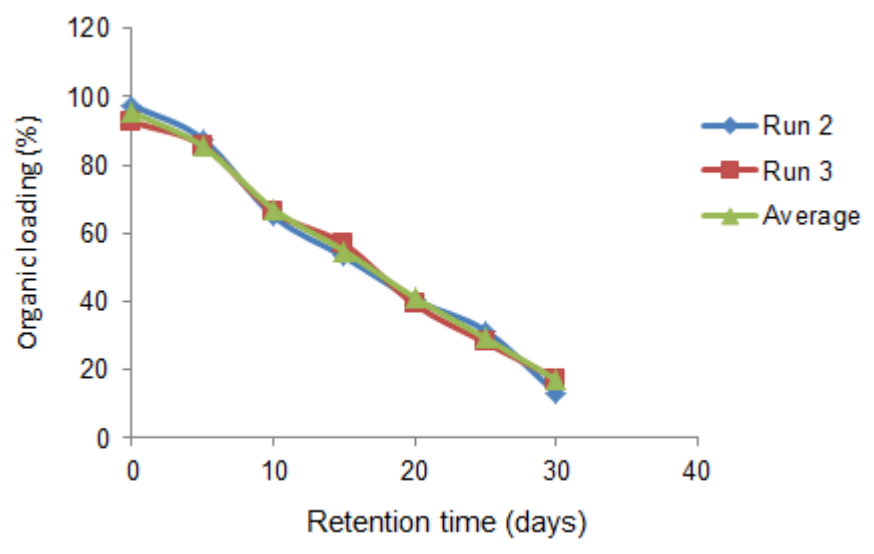

Figure 2. Organic Carbon Loading Variation during Anaerobic Digestion

\subsubsection{Moisture Content}

The average moisture content of the bio waste increased from about $30.3 \%$ to $60.7 \%$ with standard deviation values ranging between 0.20-0.65 during the anaerobic digestion process (Figure 3). During anaerobic digestion, water is generated as by product due to the exothermic nature of the process and condenses in the digester resulting in increased moisture content of the digested bio waste (Sajeena et al., 2013). If further utilization for example use as bio fertilizers, the digestate obtained is required then further dewatering processes must be done. 


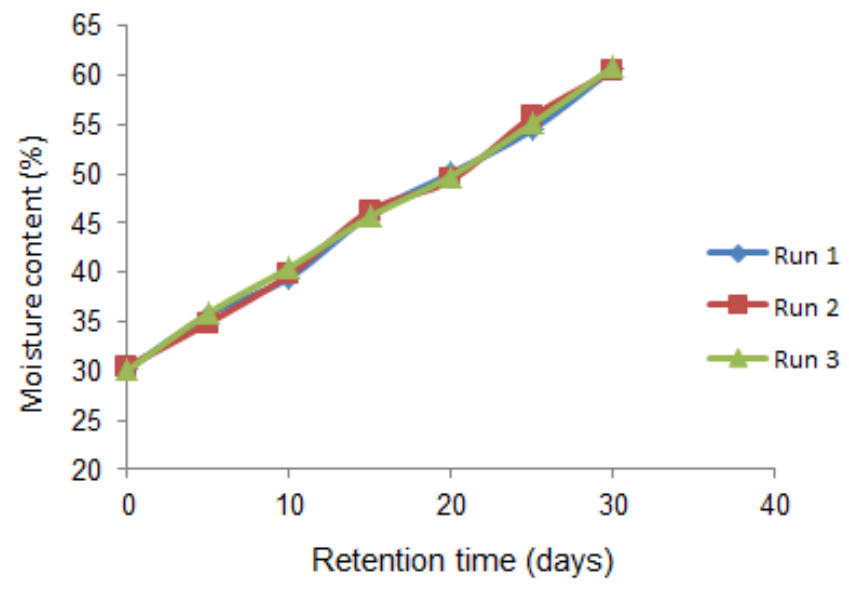

Figure 3. Moisture Content Variation during Anaerobic Digestion

\subsection{3 pH}

The bio waste $\mathrm{pH}$ changed from being acidic (6.1-6.2) to neutral (7.5-7.6) during the anaerobic digestion process (Figure 4). Hycura has also been reported to neutralize the $\mathrm{pH}$ of the digestion media during biogas production (Manyuchi et al., 2015).

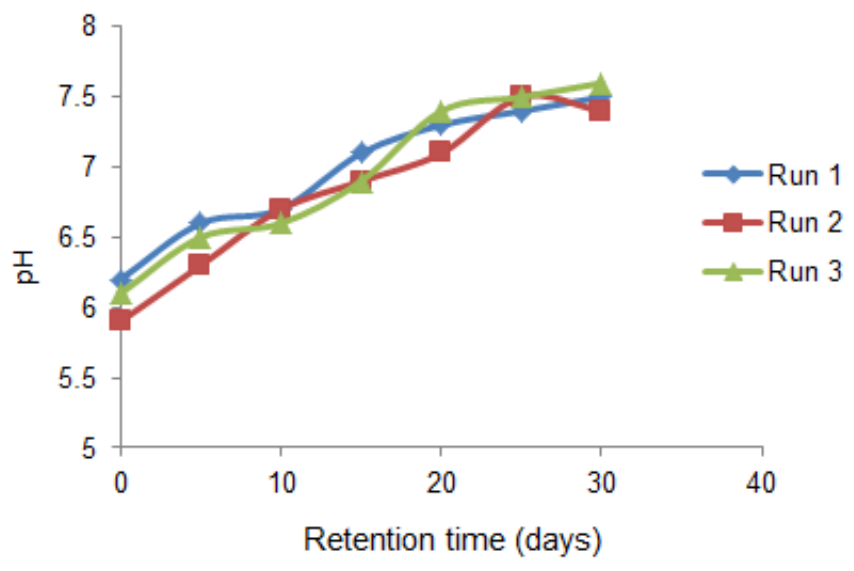

Figure 4. pH Variation during Anaerobic Digestion of Bio Waste

\subsubsection{Chemical Oxygen Demand}

In this study, the bio-waste COD reduced by $87 \%$ upon digestion for a retention period of 30 days (Figure 5). This was attributed to the digestion of the bio waste during the biogas production process enhanced by the Hycura effects. Hycura has been reported to lower COD in bio waste by more than $90 \%$ as the digestion and stabilization of organic matter progressed over time (Manyuchi et al., 2015). Babaee and Shayegan (2011) also reported an $88 \%$ decrease in COD upon digestion of vegetable waste at $34^{\circ} \mathrm{C}$ for a retention period of 55 days. 


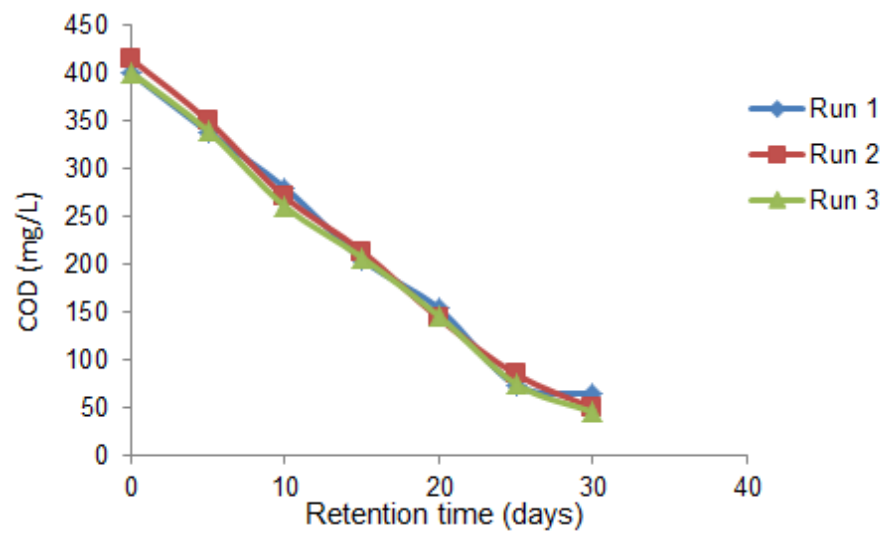

Figure 5. COD Variation during Bio Waste Anaerobic Digestion

\subsubsection{Total Solids}

The total solids content of the bio waste decreased by approximately $54 \%$ during the co-digestion process (Figure 6). Sajeena et al. (2013) reported TS reductions of between 71-80\% during biogas production from municipal waste. During the anaerobic digestion process, the solids are converted to biogas and in this study the rate of digestion was enhanced by the addition of Hycura. Hycura tends to be activated and the granules since they are living organisms tend to grow rapidly utilizing the nutrients in the bio waste (Manyuchi et al., 2015).

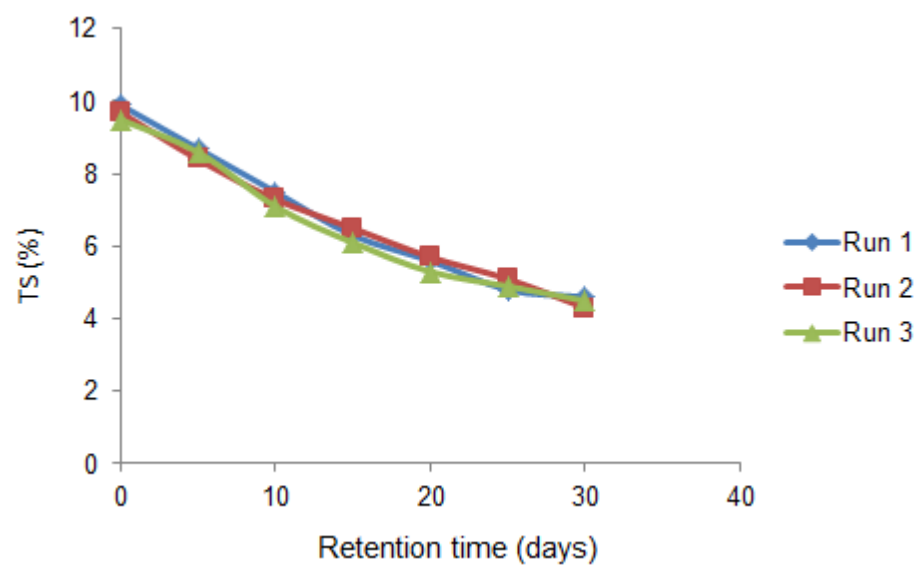

Figure 6. TS Variation during Bio Waste Anaerobic Digestion

\subsubsection{Volatile Solids}

The volatile solids of the bio waste decreased by approximately $80 \%$ during the co-digestion process as a result of the volatization and digestion of the bio waste. Studies by Babaee and Shayegan (2013) also reported an $88 \%$ decrease in volatile solids upon digestion of vegetable waste at $34{ }^{\circ} \mathrm{C}$. 


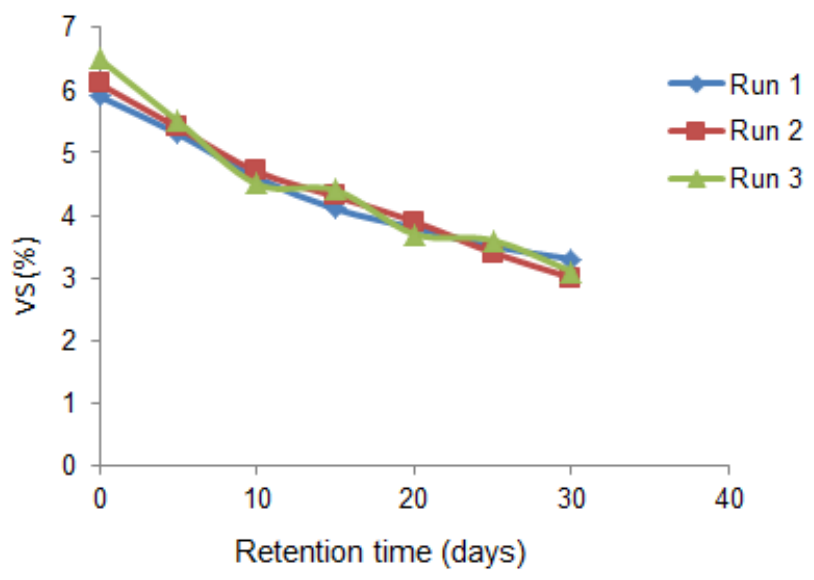

Figure 7. VS variation during bio waste anaerobic digestion

A summary of the characteristics of the bio waste before and after digestion are shown in Table 1.

Table 1. Characteristics of the Bio Waste

\begin{tabular}{|c|c|c|}
\hline Parameter & $\begin{array}{c}\text { Before } \\
\text { digestion }\end{array}$ & $\begin{array}{c}\text { After } \\
\text { digestion }\end{array}$ \\
\hline Moisture content (\%) & $30.3 \pm 0.2$ & $60.6 \pm 0.2$ \\
\hline $\mathrm{pH}(-)$ & $6.1 \pm 0.2$ & $7.5 \pm 0.1$ \\
\hline COD (mg/L) & $405.7 \pm 8.3$ & $53.7 \pm 9.9$ \\
\hline Total solids (\%) & $9.7 \pm 0.2$ & $4.5 \pm 0.2$ \\
\hline Total volatile solids & $95.4 \pm 2.5$ & $17.1 \pm 3.8$ \\
$(\%)$ & & \\
\hline
\end{tabular}

\subsection{Biogas Generation from Kitchen and Sewage Sludge Bio Waste}

\subsubsection{Effect of Hycura on Biogas Production}

The cumulative biogas produced from the bio waste increased with increase in the anaerobic digestion retention time for both cases with and without Hycura inoculation (Figure 8). This was attributed to the increase in the decomposition of the total solids and organic matter as attributed by the decrease in TS, COD organic loading. However, higher amounts of biogas were achieved in a system inoculated with Hycura; the $50 \%$ increase was attributed to the bio catalytic effect of Hycura hence increased biogas generation. 


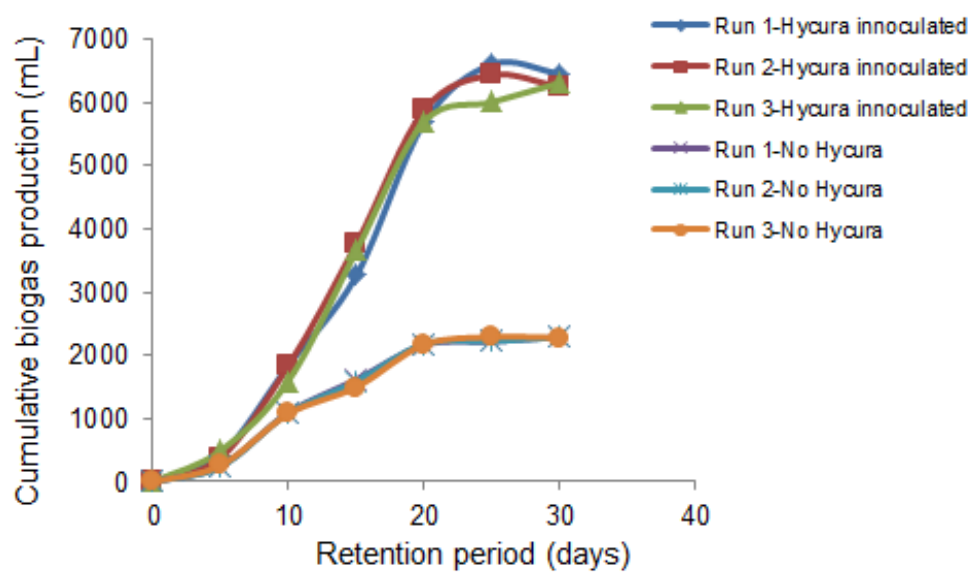

Figure 8. Effect of Hycura on biogas production

\subsubsection{Biogas Composition}

The biogas from the co-digestion of kitchen and sewage sludge bio waste had a methane content of $70-74 \%$ which is considered to be very high in comparison to methane values reported in literature. Subramani and Nallathambi (2012) reported a biogas composition with methane 50-65\% after co-digestion of sewage and kitchen waste, a methane composition which is $13 \%$ in comparison to this study. The high methane content was attributed to the enhanced effects by Hycura's bio catalysis effect (Manyuchi et al., 2015). It was also assumed that the interactive effect by the microorganisms from the bio waste enhanced the anaerobic digestion process In addition, the biogas had low values of $\mathrm{H}_{2} \mathrm{~S}$ and this was attributed to the hindering effect of Hycura in producing $\mathrm{H}_{2} \mathrm{~S}$. The composition of the biogas is given in Table 2 .

Table 2. Composition of the Biogas

\begin{tabular}{|c|c|c|}
\hline $\begin{array}{c}\text { Gas composition } \\
(\%)\end{array}$ & $\begin{array}{c}\text { Hycura } \\
\text { inoculated }\end{array}$ & Hycura free \\
\hline Methane $\left(\mathrm{CH}_{4}\right)$ & $70-74$ & $55-60$ \\
\hline $\begin{array}{c}\text { Carbon dioxide } \\
\left(\mathrm{CO}_{2}\right)\end{array}$ & $20-25$ & $35-40$ \\
\hline $\begin{array}{c}\text { Hydrogen sulphide } \\
\left(\mathrm{H}_{2} \mathrm{~S}\right)\end{array}$ & $1-2$ & $5-5$ \\
\hline Oxygen $\left(\mathrm{O}_{2}\right)$ & $0.2-0.3$ & $0.5-0.07$ \\
\hline Water $\left(\mathrm{H}_{2} \mathrm{O}\right)$ & $<0.01$ & $<0.05$ \\
\hline
\end{tabular}

\section{CONCLUSION}

High methane content biogas can be obtained from the digestion of kitchen and sewage sludge bio waste to achieve methane composition as high as $74 \%$. Co-digestion of sewage sludge with kitchen bio waste enhances biogas production and promotes waste management especially with the addition of Hycura as a co-digestion catalyst enhances the bio methane composition in the biogas and reduces the amount of contaminants. Biogas production from kitchen and sewage sludge bio waste promotes sustainable development at the same time mitigating climate change. 


\section{REFERENCES}

APHA. Standard methods for the examination of water and wastewater, $21^{\text {st }}$ Edition, America Public Health Association, American Water Works, Association, Water Environment Federation, Washington, DC, USA, 2005.

Apte, A., Cheernam, V., Kamat, M., Kamat, S., Kashikar, P., and Jeswani, H., 2013. Potential of using kitchen waste in a biogas plant, International Journal of Environmental Science and Development, vol. 4, no. 4, pp. 370-374.

Babaee, A., and Shayegan, J., 2011. Effect of organic loading rates (OLR) on production of methane from anaerobic digestion of vegetables waste, World Renewable Energy Congress 2011-Sweden, 8-13 May 2011, Linkoping, Sweden, 2011.

Beno, Z., Boran, J., Houdkova, L., Dlabaja, T., and Sponar, J., 2009. Cofermentation of kitchen waste with sewage sludge, Chemical Engineering Transactions, vol. 18, pp. 677-682.

Das, A., and Mondal, C., 2016. Biogas production from co-digestion of substrates: A review, International Research Journal of Environment Sciences, vol. 5, no. 1, pp. 49-57.

Deressa, L., Libsu, S., Chavan, R. B., Manaye, D., and Dabassa, A., 2015. Production of biogas from fruit and vegetable wastes mixed with different wastes, Environment and Ecology Research, vol. 3, no. 3, pp. 65-71.

Gray, M. D., Suto, P., and Pek, C.,2008. Anaerobic digestion of food waste A- 7 Funding Opportunity No. EPA-R9-WST-06-004, 2008.

Malik, D. S., and Bharti, U., 2009. Biogas production from sludge of sewage treatment plant at Haridwar (Uttarakhand), Asian Journal of Experimental Sciences, vol. 1, pp. 95-98.

Manyuchi, M. M., Ikhu-Omoregbe, D. I. O., and Oyekola, O. O., 2015. Acti-zyme biochemical properties: potential for use in anaerobic sewage treatment co-generating biogas, Asian Journal of Science and Technology, vol. 6, no. 3, pp. 1152-1154.

Muzenda, E., Bio methane generation from organic waste: A review, Proceedings of the World Congress on Engineering and Computer Science, WCES 2014. 22-24 October 2014, San Fransico, USA.

Neves, L., Ribeiro, R., Oliveira, R., and Alves, M. M., Anaerobic digestion of coffee waste. ADSW2005 Conference Proceedings - Volume 1 - Session 6b: Process Engineering, 2005.

Prabhu, M. S., and Mutnuri, S., 2016. Anaerobic co-digestion of sewage sludge and food waste, Waste Management and Research, pp. 1-9, 2016.

Sajeena, B. B., Jose, P. P., and Madhu, G., 2013. Effect of total solid concentration on anaerobic digestion of the organic fraction of municipal solid waste, International Journal of Scientific and Research Publications, vol. 3, no. 8, pp. 1-5, 2013.

Schaumann BioEnergy., Biogas Production-A Complex Process, 2013.

Subramani, T., and Nallathambi, M., 2012. Mathematical model for commercial production of biogas from sewage water and kitchen waste, International Journal of Modern Engineering Research, vol. 2, no. 4, pp. 1588-1595.

Vikrant, D., and Shekhar, P.,2013. Generation of biogas from kitchen waste -Experimental analysis, International Journal of Engineering Science Invention, vol. 2, no. 10, pp. 15-19. 